\title{
Associations of Falls with Quality of Life and Correlated Factors in Community-Dwelling Older Adults: A Two-Wave Cohort Study
}

Yih-Jian Tsai ( $D$ markus.ytsai@gmail.com )

Global Taiwanese Medical Alliance: GTMA https://orcid.org/0000-0001-5279-1113

Wen-Jung Sun

Taipei City Hospital Zhongxing Branch

Yi-Ching Yang

National Cheng Kung University College of Medicine

Pesus Chou

National Yang Ming Chiao Tung University School of Medicine

Jung-Der Wang

National Cheng Kung University College of Medicine

\section{Research Article}

Keywords: falls, quality of life, elderly

Posted Date: October 18th, 2021

DOI: https://doi.org/10.21203/rs.3.rs-966827/v1

License: (c) (1) This work is licensed under a Creative Commons Attribution 4.0 International License. Read Full License 


\section{Abstract \\ Background}

Falls contribute to disability and burden of care among older adults. Studies of fall-related impacts on quality of life (QOL) are warranted for future prevention interventions.

\section{Methods}

Fall-related data were collected from adults aged 70 years and above using questionnaire interviews in the 1996 and 1999 surveys at Hunei community in southern Taiwan. Their QOL was measured using the Short Form 36 Health Survey (SF-36) and World Health Organization Quality of Life questionnaire (WHOQOL-BREF) in the 1999 follow-up only. The bilateral relationship among fall category, selected covariates (i.e., age, sex, number of difficulties in performing activities of daily living (ADLs) or instrumental ADLs, number of comorbidities, Geriatric Depression Scale (GDS) scores, Mini-Mental Stated Examination (MMSE) scores, fear of falling, and Physical Activity Scale for the Elderly (PASE) scores), and mean QOL scores were investigated. Hierarchical linear regression models were tested to examine the associations between fall frequency and QOL with sequential entry of explanatory variables. The final models were established by substituting fall category for fall frequency.

\section{Results}

Fall category was significantly associated with physical-related subscale scores, except body pain. Almost every QOL score revealed a negative association with the number of comorbidities, GDS scores, and fear of falling; however, a positive association with MMSE and PASE scores was observed.

\section{Conclusions}

Future prevention interventions should target common risk factors of both QOL and falls among older people, including control of comorbidities, depressive symptoms, cognitive impairment, and inactivity.

\section{Background}

After a comprehensive assessment of morbidity and mortality from falls, the Global Burden of Disease Study 2017 revealed that global age-specific years lived with disability increased with age, and hip and femur fractures increasingly contribute to disability in older age groups [1]. As the population aged 65 and older is rapidly increasing [2], the medical costs attributable to both fatal and nonfatal falls are assumed to keep growing at the nation [3] and state levels [4]. In addition to financial impacts, falls pose an emerging threat to the quality of life (QOL) of older adults due to psychological and functional consequences, such as causing feelings of powerlessness, instilling fear of falling, and raising the need to seek care [5]. In fact, falls have a widespread and profound influence on QOL among older people, as assessed using different measurement QOL instruments. For instance, falls have had a significant impact on the physical component of the SF-12 [6] and SF-36 [7], whereas the fear of falling is associated with poor QOL for both physical component summary (PCS) and mental component summary (MCS) of the SF-36 [7]. The World Health Organization Quality of Life questionnaire (WHOQOL-BREF) effectively distinguishes fallers from non-fallers in terms of QOL scores among older adults in low-income communities [8, 9]. Moreover, the strength of association between falls and impairments in the Euro-QOL (EQ-5D)-rated QOL varies across fall category, with a significant mean score difference between each pair of fall category (10).

Noteworthily, the relationship between falls and QOL is confounded by many risk factors, including advanced age, female gender, falling history, fear of falling, and history of diabetes and arthritis [7]. Other risk factors for falls, including difficulty in performing one basic ADL, difficulty in performing two or more instrumental ADLs (IADLs), comorbidities, and depressive symptoms [11], are also supposed to lead to poor QOL. For example, disability in ADL and IADL is negatively associated with QOL in older people aged 75 years and older [12]. Comorbidities have a negative effect on the general adult population in terms of the EQ-5D-5L [13] and the CDC HRQOL-4 (i.e., general health, mental distress, physical distress, and activity limitations) [14]. A significant negative correlation between depressive symptoms and EQ-5D scores was found among rural older people in central China [15]. Moreover, recent studies on the relationship between cognitive function and QOL have shown that older adults with cognitive complaints tended to perceive lower general mental wellbeing (SF-12 MCS) [16], and cognitive impairment was associated with poor scores on the physical and psychological domains of WHOQOL-BREF [17]. An 18-month panel study has revealed that physical activity would indirectly influence global QOL across time via more proximal outcomes of physical activity, including self-efficacy, disability limitations, and physical self-worth [18].

However, the relationship between falls and QOL has received insufficient attention. Most multivariate models of the preceding studies were not completely adjusted for the aforementioned confounding factors to differentiate the subscale effect of single fall and recurrent falls on QOL. To bridge the gap of knowledge, this study was designed to examine the associations between fall category and every subscale QOL using the SF-36 and WHOQOL-BREF with sufficient adjustment for selected covariates in community-dwelling older adults in southern Taiwan.

\section{Methods}

Study subjects and data collection 
Data used were collected from a two-wave cohort study conducted at Hunei, Kaohsiung, in southern Taiwan. The Hunei community is located in northern Kaohsiung and people mainly relied on agriculture and fishery for a livelihood. The eligibility criteria were as follows: community-dwellers aged 70 and older and had lived for more than 6 months with local household registration. Meanwhile, the exclusion criteria included individuals who were hospitalized, those who had moved, and those who lived in institutions. From September 1996 to April 1997, 1,092 older adults finished the first-wave survey for face-to-face questionnaire interviews, of which the content included age, sex, number of ADL (activities of daily living) /IADL (instrumental ADL) difficulties, and fall experience in the previous year, among others. Among them, only 600 persons (54.9\%) completed a follow-up from November 1999 to May 2000 . The secondwave survey questionnaire consisted of the SF-36 and WHOQOL-BREF scales, comorbidities, depressive symptoms, cognitive impairment, fear of falling, and physical activities, among others, in addition to fall experience. However, 492 persons were lost to follow-up due to death $(n=304)$ and unknown causes ( $\mathrm{n}=$ 188). Informed consent was obtained before questionnaire administration to each participant.

\section{Measurement instruments of QOL}

The QOL of the study participants was measured using the SF-36 and WHOQOL-BREF. The SF-36 measures eight dimensions of health: physical functioning (PF), role physical (RP), body pain (BP), general health (GH), vitality (VT), social functioning (SF), role emotional (RE), and mental health (MH). Raw scores were transformed into a score from 0 to 100 , with higher scores reflecting better health. Although the SF-36 has been recommended for its validity and feasibility [19, 20], it was translated and developed according to the standard methodology of the International Quality of Life Assessment project [21].

The Taiwanese version of the WHOQOL-BREF used in this study was originally developed by Yao et al. [22] from the original WHOQOL-BREF [23-25]. It consists of 28 items, including the 26 standard WHOQOL-BREF items for assessing QOL in four domains: Physical (Phy), Psychological (Psy), Social relations (Soc) and Environmental (Env). Two additional items were added to reflect unique cultural characteristics in Taiwan: being respected/accepted by others and eating what one loves to eat. Reliability and cross-validation examination had shown that the Taiwanese version of the WHOQOL-BREF is analogous to the global version [26]. Each item of the scale uses a five-point Likert-type response measurement. Item scores are equivalent to facet scores; however, domain scores were calculated from the average of the item/facet scores in the same domain multiplied by 4 so that the final range of the transformed domain score lies between 4 and 20. A higher score indicates better QOL [22]. The WHOQOL-BREF is a suitable method for assessing health-related QOL for communitydwelling older persons in central Taiwan [27].

Relatively minor modifications were made to make the SF-36 more relevant to the Taiwanese culture, as was done in other studies [28-30]. For example, TaiChi Chuan was substituted for playing golf, and "mile" was changed to "kilometer." The SF-36 used in this study was validated [31-32], and its scoring and interpretation followed the SF-36 manual [33]. Similarly, the WHOQOL-BREF was further translated from Mandarin Chinese into the Taiwanese dialect by local interviewers and an advisory panel of experts before it was administered to the interviewees. In this study, physical-related subscales were defined to include PF, RP, BP, GH, PCS, and Phy, whereas psychological-related subscales include VT, SF, RE, MH, MCS, and Psy.

\section{Fall measures and covariates}

A fall was defined as "an event of falling down to a lower surface that occurs while one stands up, sits down, gets into bed, walks, etc., regardless of its underlying causes." The number of falls reported in the two surveys was summed as fall frequency, which was further grouped into fall category, including three categories: no falls (NF), single fall (one fall (OF)), and recurrent falls (RF) (two or more falls).

Covariates chosen for the correlation analyses included sociodemographic characteristics (age, sex, the number of ADL difficulties, and the number of IADL difficulties), medical factors (the number of comorbidities, depressive symptoms [34], cognitive impairment [35], and fear of falling), and a lifestyle factor (physical activity level, measured using the Physical Activity Scale in the Elderly (PASE) [36] (Additional file 1: Table S1).

\section{Statistical analyses}

The distribution and mean with standard deviation of sociodemographic characteristics and assessment scores and prevalence by fall category were presented. The chi-square test was used, as appropriate, to differentiate fall category by the aforementioned covariates. Differences in the mean QOL scores were examined using one-way analysis of variance (ANOVA) or Student's t test not only across the fall category but also across the selected covariates. A series of hierarchical linear regression models was tested to examine the associations between falls and QOL with a sequential entry of fall frequency and sociodemographic, medical, and lifestyle covariates. The final models were established by substituting fall category for fall frequency to differentiate the effect of single fall from that of RF. All statistical analyses were conducted using STATA/SE 17 for Windows. The statistical significance level (a) was set at 0.05 .

\section{Results}

Despite a similar sex distribution, the age distribution of the 492 nonrespondents was respectively 41,23 , and $36 \%$ for those aged $70-74,75-79$, and $\geq 80$ years, significantly differing from that of respondents (chi-square test; $p<0.05$ ). In the 600 respondents who completed the follow-up, the mean baseline age was $76.2 \pm 4.6$ years with a range of $70-96$ years (Table 1 ). Moreover, $50.8 \%$ were females, and $40.7 \%$ were afraid of falling. They had $0.1 \pm 0.9$ ADL difficulty, 0.7 \pm 1.5 IADL difficulty, $1.4 \pm 1.1$ comorbidities, and a mean score of $4.3 \pm 3.8$ for the GDS, $21.8 \pm 7.9$ for the MMSE, and $55.4 \pm 59.3$ for the PASE. Among them, 125 were fallers $(20.8 \%)$, including 73 single fallers and 52 recurrent fallers. Approximately $3 \%$ had difficulty in at least one ADL task, and $34 \%$ had difficulty in at least one IADL task. Furthermore, $35 \%$ had depressive symptoms, $41 \%$ had either cognitive impairment or fear of falling, and approximately $65 \%$ had a moderate to high PASE score. Moreover, approximately $60 \%$ had $1-2$ comorbidities, and $15 \%$ had three comorbidities, with the following rankings according to prevalence (not shown in the table): cataract (47.8\%), hypertension (38.8\%), heart diseases (14.2\%), respiratory diseases (13.0\%), diabetes (11.7\%), gout (7.2\%), and stroke (4.5\%). 
Table 1

Distribution of the characteristics of participants and prevalence according to the fall category.

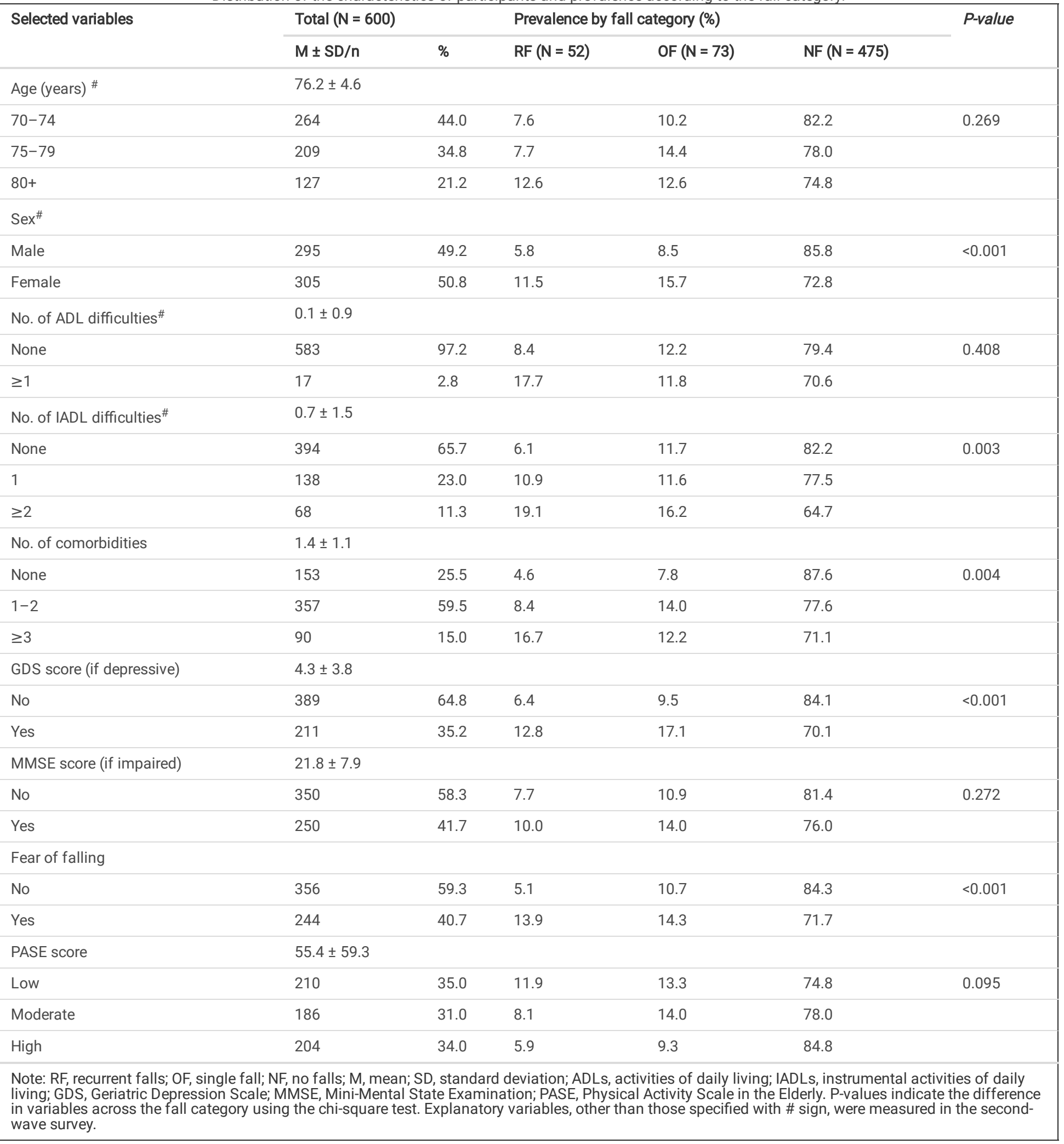

Bivariate analyses revealed that the characteristics significantly associated with the risk of falls included female gender, a higher number of IADL difficulties, a higher number of comorbidities, depressive symptoms, and fear of falling; however, age, the number of ADL difficulties, cognitive impairment, and physical activity level were not associated with fall risk. In contrast to the prevalence of RF, the prevalence of single fall did not present a smooth gradient of risk by age, the number of ADL difficulties, the number of IADL difficulties, the number of comorbidities, and physical activity level. 
Table 2 shows that every mean QOL score significantly varied according to the fall category (ANOVA; $p<0.05$ ), except for the Soc and Env domains. The highest and lowest mean QOL scores were 74.0 and 42.5 for BP and PCS, respectively, in the SF-36, whereas the corresponding mean subscale scores were 13.8 for the Soc domain and 12.9 for the Psy domain in the WHOQOL-BREF. Although both recurrent and single fallers tended to have a lower mean QOL score than non-fallers in most subscales (except for VT, MH, Psy, Soc, and Env), no significant difference was observed between recurrent and single fallers (Scheffé multiple-comparison test; $p>0.05$ ).

Table 2

Mean subscale scores of SF-36 and WHOQOL-BREF by fall category.

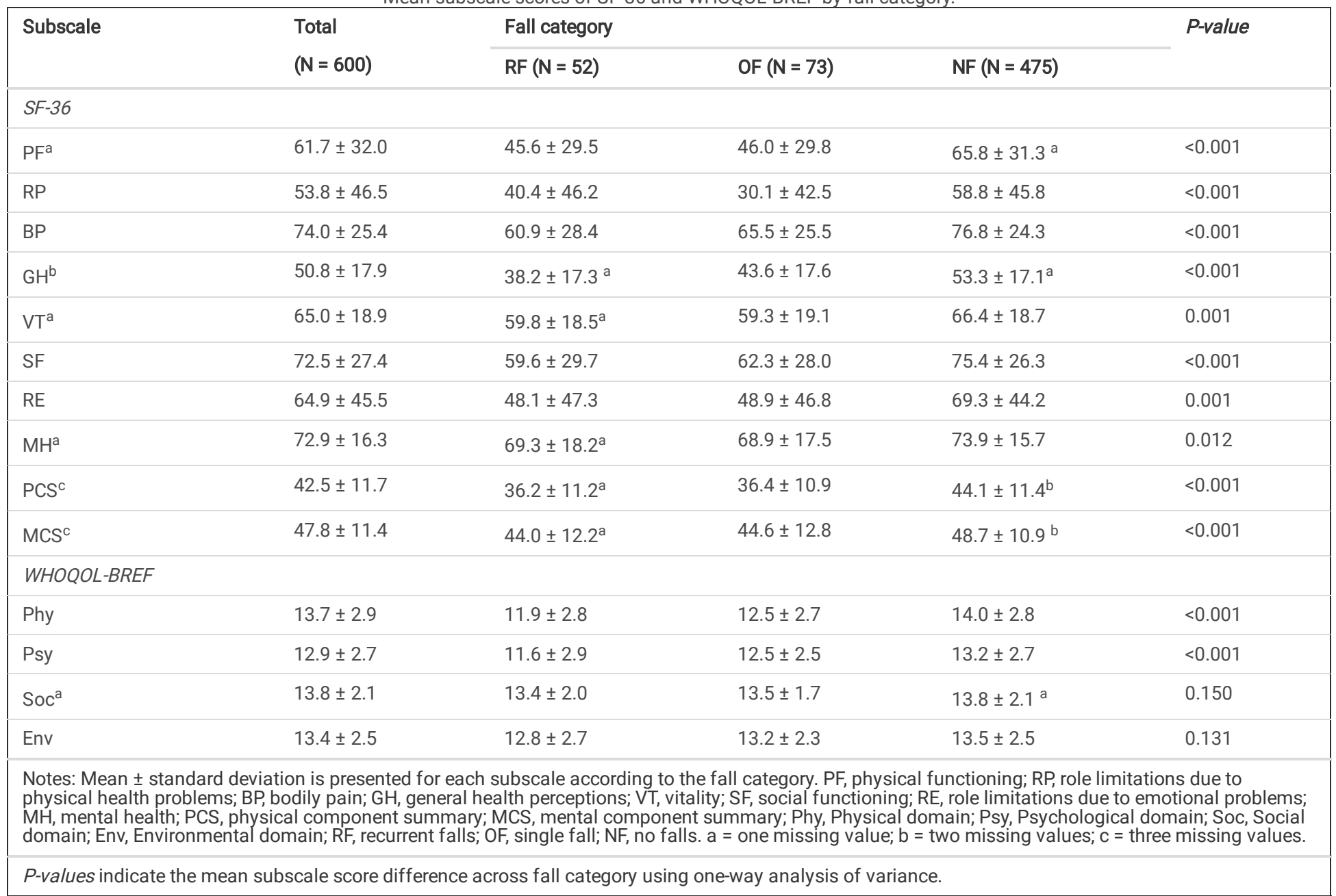

Individuals who were more advanced in age, female, with difficulty in at least one ADL/IADL task, with more comorbidities, with depressive symptoms, with cognitive impairment, and with fear of falling tended to have a lower mean QOL score than their counterparts, with only a few exceptions. In contrast, older people who had a high PASE score tended to have a higher mean QOL score, followed by those with a moderate PASE score and those with a low PASE score (Additional file 2: Table S2).

Table 3 shows the results of the hierarchical linear regression models for every QOL subscale. With a sequential entry of fall frequency and sociodemographic, medical, and lifestyle variables, the proportions of the total amount of variance explained gradually increased, and the effect of fall frequency declined in the models after initiation. However, the partial regression coefficients of fall frequency remained significantly negative for GH, PCS, and Phy only in the full models. 
Table 3

Associations between fall frequency and every subscale of QOL by hierarchical linear regression models.

\begin{tabular}{|c|c|c|c|c|c|c|c|c|c|c|c|c|c|}
\hline \multirow{2}{*}{$\begin{array}{l}\text { Fall } \\
\text { frequency }\end{array}$} & \multicolumn{10}{|l|}{ SF-36 } & \multicolumn{3}{|c|}{ WHOQOL-BREF } \\
\hline & PF & RP & BP & GH & VT & SF & RE & $\mathrm{MH}$ & PCS & MCS & $\mathrm{PH}$ & PS & SR \\
\hline \multicolumn{14}{|l|}{ Model 1} \\
\hline $\begin{array}{l}\text { Fall } \\
\text { frequency }\end{array}$ & $-4.81^{\star \star \star}$ & $-5.17 \star \star$ & $-3.51^{\star \star \star}$ & $-3.56^{\star \star \star}$ & 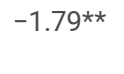 & $-3.75^{\star \star \star}$ & $-5.16^{\star \star}$ & $-1.21^{*}$ & $-1.89 * \star \star$ & $-1.14^{\star \star}$ & $-0.50 \star \star \star$ & $-0.32^{\star \star}$ & $-0.1 \%$ \\
\hline $\mathrm{R}^{2}$ & 0.03 & 0.02 & 0.03 & 0.05 & 0.01 & 0.03 & 0.02 & 0.01 & 0.03 & 0.01 & 0.04 & 0.02 & 0.00 \\
\hline \multicolumn{14}{|l|}{ Model 2} \\
\hline $\begin{array}{l}\text { Fall } \\
\text { frequency }\end{array}$ & $-3.55^{\star \star \star}$ & $-3.80^{\star}$ & $-2.84^{\star \star}$ & 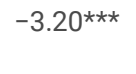 & -1.28 & $-2.81^{\star *}$ & $-3.96^{*}$ & -0.79 & $-1.49 \star \star \star$ & $-0.83^{*}$ & $-0.42^{\star \star \star}$ & $-0.26^{*}$ & -0.0 s \\
\hline $\mathrm{R}^{2}$ & 0.27 & 0.13 & 0.09 & 0.10 & 0.08 & 0.19 & 0.12 & 0.06 & 0.18 & 0.09 & 0.17 & 0.08 & 0.03 \\
\hline \multicolumn{14}{|l|}{ Model 3} \\
\hline $\begin{array}{l}\text { Fall } \\
\text { frequency }\end{array}$ & -1.41 & -0.94 & -1.01 & -1.70 ** & 0.30 & -0.77 & -0.94 & 0.56 & $-0.72^{\star}$ & 0.14 & $-0.19 * \star$ & -0.04 & 0.04 \\
\hline $\mathrm{R}^{2}$ & 0.52 & 0.35 & 0.35 & 0.41 & 0.47 & 0.51 & 0.36 & 0.41 & 0.43 & 0.49 & 0.55 & 0.52 & 0.30 \\
\hline \multicolumn{14}{|l|}{ Model 4} \\
\hline $\begin{array}{l}\text { Fall } \\
\text { frequency }\end{array}$ & -1.23 & -0.80 & -0.94 & $-1.66^{\star \star}$ & 0.35 & -0.66 & -0.73 & 0.56 & $-0.67^{*}$ & 0.17 & -0.18 ** & -0.04 & 0.03 \\
\hline$R^{2}$ & 0.58 & 0.36 & 0.36 & 0.42 & 0.48 & 0.54 & 0.40 & 0.41 & 0.46 & 0.50 & 0.57 & 0.52 & 0.31 \\
\hline
\end{tabular}

In the final models adjusted for fall category and the selected covariates, the proportions of total QOL variation collectively explained were between 0.5 and 0.7 for PF, SF, and MCS and the Phys and Psy domains and between 0.3 and 0.5 for the other subscales (Table 4). Relative to NF, one unit change in a single fall was significantly associated with losses of 10.28 PF scores, 17.05 RP scores, $4.93 \mathrm{GH}$ scores, 4.62 PCS scores, and 0.65 Phy domain scores, whereas one unit change in RF was associated with losses of $6.17 \mathrm{GH}$ scores and 0.59 Phy domain score. 
Table 4

Multiple linear regression models for each subscale of SF-36 and WHOQOL-BREF.

\begin{tabular}{|c|c|c|c|c|c|c|c|c|c|c|c|c|}
\hline & PF & RP & BP & GH & VT & SF & RE & $\mathrm{MH}$ & PCS & MCS & Phy & $\mathbf{P}$ \\
\hline \multicolumn{13}{|l|}{ Fall category } \\
\hline OF vs. NF & $-10.28^{\star \star \star}$ & $-17.05^{\star \star \star}$ & -3.93 & $-4.93^{\star \star}$ & -0.67 & -4.62 & -7.57 & 0.17 & $-4.62^{\star \star \star}$ & -0.06 & $-0.65^{\star \star}$ & 0 \\
\hline RF vs. NF & -1.86 & 3.22 & -3.81 & $-6.17 * \star$ & 3.85 & -0.13 & 0.90 & 3.50 & -1.85 & 1.77 & $-0.59 *$ & - \\
\hline Age & 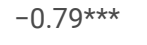 & -0.68 & 0.06 & 0.08 & -0.07 & -0.26 & -0.33 & 0.11 & $-0.22^{*}$ & 0.02 & -0.01 & 0 \\
\hline Sex & -2.12 & -1.47 & -3.51 & 1.78 & -1.95 & 0.07 & -3.54 & $-2.81^{\star}$ & -0.16 & -1.36 & 0.29 & 0 \\
\hline $\begin{array}{l}\text { No. ADL } \\
\text { difficulty }\end{array}$ & -1.19 & -1.72 & 0.37 & 1.35 & 0.48 & 0.19 & -2.97 & $1.93^{\star \star}$ & -0.22 & 0.17 & -0.08 & 0 \\
\hline $\begin{array}{l}\text { No. IADL } \\
\text { difficulty }\end{array}$ & $-3.23^{\star \star \star *}$ & -1.06 & 0.29 & -0.37 & -0.09 & $-2.46^{\star \star \star *}$ & -0.82 & -0.72 & -0.53 & -0.29 & $-0.16^{\star}$ & - \\
\hline $\begin{array}{l}\text { No. of } \\
\text { comorbidities }\end{array}$ & $-2.11^{\star \star}$ & $-5.48^{\star \star \star}$ & $-2.89 * \star \star$ & $-3.27 * \star \star$ & $-1.03^{\star}$ & $-2.19 \star \star$ & $-3.02^{\star}$ & $-0.96^{\star}$ & $-1.51^{\star \star \star}$ & $-0.62^{\star}$ & 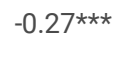 & - \\
\hline GDS score & $-2.43^{\star \star \star}$ & $-3.21^{\star \star \star}$ & $-2.36^{\star \star \star}$ & $-1.63^{\star \star \star}$ & 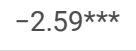 & $-2.86^{\star \star \star}$ & $-4.10^{\star \star \star}$ & $-2.27^{\star \star \star}$ & $-0.76^{\star \star \star}$ & $-1.60 * \star \star$ & $-0.33^{\star \star \star}$ & - \\
\hline MMSE score & $0.46^{* *}$ & $1.13^{\star \star \star}$ & $0.32^{\star}$ & 0.31 ** & 0.07 & $0.45^{\star \star \star}$ & $0.52^{\star}$ & $-0.21^{*}$ & 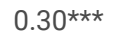 & -0.00 & 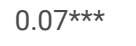 & 0 \\
\hline $\begin{array}{l}\text { Fear of } \\
\text { falling }\end{array}$ & $-12.54^{\star \star \star}$ & $-12.33^{\text {** }}$ & $-7.31^{\star \star \star}$ & $-5.87 * \star \star$ & $-6.64^{\star \star *}$ & $-8.76^{\star \star \star}$ & 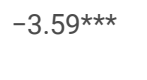 & $-5.74^{\star \star \star}$ & $-3.65^{\star \star \star}$ & $-3.91^{\star \star \star}$ & $-0.95^{\star \star \star}$ & - \\
\hline PASE score & $0.14^{\star \star \star}$ & $0.11^{\star \star \star}$ & $0.06^{\star \star \star}$ & $0.03^{*}$ & $0.04^{\star \star \star}$ & $0.09 \star \star \star$ & $0.16^{\star \star *}$ & 0.00 & $0.04 * \star \star$ & $0.03^{\star \star \star}$ & $0.01^{\star \star \star}$ & - \\
\hline Constant & $142.12^{\star \star \star}$ & $118.32^{\star \star *}$ & $89.39 * * *$ & $54.96 * \star \star$ & $91.11 * * *$ & $107.41^{\star \star *}$ & $117.66^{\star \star \star}$ & $92.13^{\star * *}$ & $62.23^{\star \star \star}$ & $60.30 * * *$ & $15.35^{\star \star \star}$ & 1 \\
\hline$R^{2}$ & 0.59 & 0.38 & 0.36 & 0.42 & 0.49 & 0.54 & 0.40 & 0.41 & 0.47 & 0.51 & 0.57 & 0 \\
\hline$F$ & $75.28 * \star \star$ & $32.50 * \star \star$ & $30.56^{\star \star \star}$ & 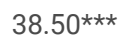 & 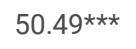 & $63.01 * \star \star$ & $35.95^{\star \star \star}$ & $37.21^{\star \star \star}$ & $47.23^{\star \star \star}$ & $54.4^{\star \star \star}$ & $70.49 * \star \star$ & 5 \\
\hline
\end{tabular}

Note: Every multiple linear regression model was adjusted for fall category, age, sex, number of ADL difficulty, number of IADL difficulty, number of comorbidi fear of falling, and PASE score. Sex was coded as 1 for male and 2 for female.

${ }^{\star} p<.05 ; * \star p<.01 ; * \star \star p<.001$.

Moreover, age was negatively correlated with PF and PCS only but was positively correlated with the Psy domain (Table 4). Compared with older men, older women were negatively associated with $\mathrm{MH}$ but were positively associated with the Psy and Soc domains. The number of IADL difficulties was negatively associated with PF and SF and the Phy and Psy domains. In contrast, the number of ADL difficulties was positively associated with MH. Moreover, every subscale score of the SF-36 revealed a universal negative association with the number of comorbidities, GDS scores, and fear of falling and a universal positive association with MMSE (except for MH and MCS) and PASE scores. Fear of falling had the greatest inverse association with QOL ratings among all covariates. However, for the WHOQOL-BREF, the number of comorbidities was negatively associated with the Phy domain, but not with the other domains. GDS scores were negatively correlated with every QOL score. Despite a positive association with most subscale QOL, PASE scores had a negative association with the Soc and Env domains.

\section{Discussion}

The study contributes to limited fall-related QOL research among community-dwelling older adults that the associations between fall category with QOL varied according to the subscales of the SF-36 and WHOQOL-BREF. Multiple linear regression analyses revealed that the fall category was significantly associated with physical-related subscale scores, except for BP. Furthermore, almost every subscale score of QOL revealed a negative association with the number of comorbidities, GDS scores, and fear of falling and a positive association with MMSE and PASE scores.

Probably due to a higher proportion of loss of follow-up among those aged $\geq 80$ years, the prevalence of single fall did not present a smooth gradient of risk as that of RF, by age, the number of ADL/IADL difficulties, the number of comorbidities, and physical activity level. Compared with those in a preceding study [37], our participants tended to have lower age-specific mean QOL in each subscale of the SF-36, but not in the WHOQOL-BREF. The influence of falls was displayed on the physical-related subscales only in multiple linear regression analyses, in contrast to the universal influence of fear of falling on every subscale. It not only conforms to the previous report that the impact of falling episodes was mainly presented on PCS and that of fear of falling on both PCS and MCS [7] but also strengthens the assertion that the SF-36 seems to be more suitable for QOL measurement of community-dwelling older adults than the WHOQOL-BREF, even though both measurement tools offer good validity and reliability [37]. The coefficients of determination increased with including medical variables into the modeling process, probably because they were associated with poor QOL in preceding studies, in terms of chronic disease [10,37], depression [38], cognitive impairment [16, 17], and fear of falling [39-41]

However, compared with previous studies [7, 10], the other subscales in this study were not as responsive to fall category as the physical-related subscales in the multiple linear regression models. Moreover, no significant inverse trend was observed between fall frequency and each subscale score in the full models of hierarchical linear regression analyses, except for GH and PCS and the Phy domain. The discrepancy might be elucidated as follows: First, according to the 
underlying mechanism of falls leading to poor QOL $[42,43]$, the fall-related influence on psychological-related subscales is assumed to lag behind that on the physical-related subscales. Second, compared with either non-fallers or single fallers, recurrent fallers might be more likely to withdraw from follow-up due to medical factors and leave their QOL deterioration under-presented. Hereby, analysis of the mean subscale score did not distinguish recurrent fallers from single fallers in Table 2. Third, some fallers could benefit from the buffering effects of favorable perceived social support [44].

Compatible with two previous studies [7, 45], a negative association was found between age and PF/PCS and between sex and MH. Further study is needed to determine whether the positive associations between age and the Psy domain and sex and the Psy/Soc domain reflected psychological resilience [46]. In contrast to Gobbens [12], a positive association was found between the number of ADL difficulties and MH. Three explanations are posed. First, it is probably due to selective survival [47]. Second, the sample size of older adults having ADL difficulties was too small to obtain a stable estimate. Third, it could reflect a phenomenon of disability paradox [48].

The beneficial effects of physical activities were underpinned by their positive association with each subscale score of the SF-36 and with the Phys domain of the WHOQOL-BREF. The reason is that exercise and physical activities help reduce the risk of developing numerous chronic conditions, offset loss in muscle mass and strength, counteract age-related decline in bone mineral density, preserve cognitive function, alleviate symptoms and behaviors associated with depression, and contribute to successful aging [49].

This study has two strengths. First, both the SF-36 and WHOQOL-BREF had been considerably modified to reflect the unique local culture. Second, these multiple linear regression models made differentiating the effects of single fall from those of RF on QOL for inter-subscale comparison possible. Nevertheless, several limitations of the study are worth considering. First, data collection based on self-perception is susceptible to recall bias, especially when several batteries of assessment items make interviewees committed to different recalling periods, such as 7 days for the GDS and PASE scales, 2 weeks for the WHOQOL-BREF, and 1 month for the SF-36. Second, the lack of repeated measurements of QOL and the selected covariates makes detecting their timedependent changes due to falls difficult. Third, no ascertainment of falls was performed between the first- and second-wave surveys when some non-fallers or single fallers could have experienced one or more falls and resulted in the misclassification of fall category and underestimation of the impacts of recurrent fallers. Fourth, the lump sum of comorbidities does not reflect the real impact of each disease because not all chronic conditions affect QOL with similar magnitudes. For example, stroke might lower down QOL more severely than simple hypertension or metabolic syndrome, whereas diabetes without any complication might not affect QOL. Therefore, the generalization of the results of this study to other community-dwelling older adults might be restricted. Whether multidimensional QOL should be regularly assessed as a surrogate outcome indicator of fall risk evaluation and management for communitydwelling older adults should be assessed [50].

\section{Conclusions}

This is the first community-based prospective study that has used the SF-36 and WHOQOL-BREF to differentiate the subscale impacts of fall category on QOL, with sufficient adjustment for selected sociodemographic, medical, and lifestyle covariates. The results of this study demonstrated that fall-related impacts mainly influence the physical-related subscales and underscore the importance of future prevention interventions targeting multiple risk factors influencing both QOL and falls among community-dwelling older people, including control of comorbidities, depressive symptoms, cognitive impairment, and inactivity.

\section{Abbreviations}

QOL: quality of life; ADL: activities of daily living; IADL: instrumental activities of daily living; GDS: Geriatric Depression Scale; MMSE: Mini-Mental State Examination; PASE: Physical Activity Scale in the Elderly; SF-36: The Short Form 36 Health Survey; PF: physical functioning; RP: role limitations due to physical health problems; BP: bodily pain; GH: general health perceptions; VT: vitality; SF: social functioning; RE: role limitations due to emotional problems; MH: mental health; PCS: physical component summary; MCS: mental component summary; WHOQOL-BREF: World Health Organization Quality of Life questionnaire-BREF; Phy: Physical domain; Psy: Psychological domain; Soc: Social domain; Env: Environmental domain; RF: recurrent falls; OF: single fall; NF: no falls; ANOVA: one-way analysis of variance.

\section{Declarations}

\section{Acknowledgments}

The authors are indebted to the interviewers and staff of Taiwan Provincial Institute of Family Planning (currently Surveillance, Research and Health Education Division, Health Promotion Administration, Ministry of Health and Social Welfare) and the Hunei Health Station for data collection, and Paul Wilkinson, Professor in Environmental Epidemiology Unit, Department of Social and Environmental Health Research, London School of Hygiene and Tropical Medicine for some helpful discussions and review of an earlier draft.

\section{Authors' contributions}

YJT had full access to the Hunei cohort study data, and took responsibility for the integrity of the data and data analysis. YJT, WJS, YCY, and PC were responsible for design of the study. WJS was in charge of data collection and curation. YJT drafted the manuscript and was responsible for interpretation of the data. WJS, YCY, PC, and JDW helped with the study methodology and participated in revision of the manuscript, writing review, and editing of the manuscript. All authors contributed to the critical revision of the manuscript for important intellectual content, and all approved the article submitted for publication.

\section{Funding}


This study was supported by the Taiwan Provincial Government (Technical Contract No. 007843) and the National Science Council, Taiwan (NSC 89-2320-B065-001-M56).

\section{Availability of data and materials}

YJT keeps the Hunei cohort study data.

\section{Ethical approval and consent to participate}

Informed consent was obtained from each participant, following the standardized operational procedures of questionnaire interview of the Taiwan Provincial Institute of Family Planning. The study proposals were approved after getting through the process of internal and external reviews, when no ethical concern was raised.

\section{Consent for publication}

Not applicable.

\section{Competing Interest}

The authors declare that they have no competing interests.

\section{Author details}

${ }^{1}$ Global Taiwanese Medical Alliance, Taichung, Taiwan 40873. ${ }^{2}$ Department of Family Medicine, Zhongxing Branch, Taipei City Hospital, Taipei, Taiwan 10341.

${ }^{3}$ Department of Geriatrics and Gerontology, College of Medicine, National Cheng-Kung University and Hospital, Tainan, Taiwan 70403. ${ }^{4}$ Community Medicine Research Center and Institute of Public Health, National Yang-Ming University, Peitou, Taipei, Taiwan 11221. ${ }^{5}$ Institute of Public Health, College of Medicine, National Chung-Kung University, Tainan, Taiwan 70403.

\section{References}

1. James SL, Lucchesi LR, Bisignano C, Castle CD, Dingels ZV, Fox JT, et al. The global burden of falls: global, regional and national estimates of morbidity and mortality from the Global Burden of Disease Study 2017. Inj Prev. 2020;26:i3-11. doi:10.1136/injuryprev-2019-043286.

2. U.S. Department of Health and Human Services, Administration for Community Living. Projected future growth of older population. https://acl.gov/agingand-disability-in-america/data-and-research/projected-future-growth-older-population, Accessed on August 22, 2021.

3. Florence CS, Bergen G, Atherly A, Burns E, Stevens J, Drake C. Medical Costs of Fatal and Nonfatal Falls in Older Adults. J Am Geriatr Soc. 2018 Apr;66:693-698. doi: 10.1111/jgs.15304.

4. Haddad YK, Bergen G, Florence CS. Estimating the Economic Burden Related to Older Adult Falls by State. J Public Health Manag Pract. 2019 Mar/Apr;25:E17-E24. doi: 10.1097/PHH.0000000000000816.

5. Kong KS, Lee Fk FK, Mackenzie AE, Lee DT. Psychosocial consequences of falling: the perspective of older Hong Kong Chinese who had experienced recent falls. J Adv Nurs. 2002 Feb;37:234-42. doi:10.1046/j.1365-2648.2002.02094.x.

6. Stenhagen M, Ekström H, Nordell E, Elmståhl S. Accidental falls, health-related quality of life and life satisfaction: a prospective study of the general elderly population. Arch Gerontol Geriatr. 2014;58:95-100. doi:10.1016/j.archger.2013.07.006.

7. Chang NT, Chi LY, Yang NP, Chou P. The impact of falls and fear of falling on health-related quality of life in Taiwanese elderly. J Commun Health Nurs. 2010;27:84-95. doi:10.1080/07370011003704958.

8. Lin MR, Tsai SL, Chen SY, Tzeng SJ. Risk factors for elderly falls in a rural community of central Taiwan. Taiwan J Public Health. 2002;21:73-82.

9. Ribeiro AP, de Souza ER, Atie S, de Souza AC, Schilithz AO. A influência das quedas na qualidade de vida de idosos [The influence of falls on the quality of life of the aged]. Cien Saude Colet. 2008;13:1265-73. doi:10.1590/s1413-81232008000400023. Portuguese.

10. Thiem U, Klaaßen-Mielke R, Trampisch U, Moschny A, Pientka L, Hinrichs T. Falls and EQ-5D rated quality of life in community-dwelling seniors with concurrent chronic diseases: a cross-sectional study. Health Qual Life Outcomes. 2014;12:2. doi:10.1186/1477-7525-12-2.

11. Tsai YJ, Yang PY, Yang YC, Lin MR, Wang YW. Prevalence and risk factors of falls among community-dwelling older people: results from three consecutive waves of the national health interview survey in Taiwan. BMC Geriatr. 2020;20:529. doi:10.1186/s12877-020-01922-z.

12. Gobbens RJ. Associations of ADL and IADL disability with physical and mental dimensions of quality of life in people aged 75 years and older. PeerJ. 2018 Aug 9;6:e5425. doi: 10.7717/peerj.5425.

13. Akbari Sari A, Karimi F, Emrani Z, Zeraati H, Olyaeemanesh A, Daroudi R. The impact of common chronic conditions on health-related quality of life: a general population survey in Iran using EQ-5D-5L. Cost Eff Resour Alloc. 2021;19:28. doi:10.1186/s12962-021-00282-8.

14. Chen HY, Baumgardner DJ, Rice JP. Health-related quality of life among adults with multiple chronic conditions in the United States, Behavioral Risk Factor Surveillance System, 2007. Prev Chronic Dis. 2011;8:A09.

15. Rong J, Chen G, Wang X, et al. Correlation between depressive symptoms and quality of life, and associated factors for depressive symptoms among rural elderly in Anhui, China. Clin Interv Aging. 2019;14:1901-10. https://doi.org/10.2147/CIA.S225141. 
16. Stites SD, Harkins K, Rubright JD, Karlawish J. Relationships between cognitive complaints and quality of life in older adults with mild cognitive impairment, mild Alzheimer disease dementia, and normal cognition. Alzheimer Dis Assoc Disord. 2018;32:276-83. doi:10.1097/WAD.0000000000000262.

17. Samuel R, McLachlan CS, Mahadevan U, Isaac V. Cognitive impairment and reduced quality of life among old-age groups in Southern Urban India: homebased community residents, free and paid old-age home residents. QJM. 2016;109:653-9. doi:10.1093/qjmed/hcw040.

18. Phillips SM, Wójcicki TR, McAuley E. Physical activity and quality of life in older adults: an 18-month panel analysis. Qual Life Res. 2013;22:1647-54. doi:10.1007/s11136-012-0319-z.

19. Ware JE Jr, Gandek B. Overview of the SF-36 Health Survey and the International Quality of Life Assessment (IQOLA) Project. J Clin Epidemiol. 1998;51:903-12. doi:10.1016/s0895-4356(98)00081-x.

20. Ware JE, Kosinski M, Keller SD. SF-36 Physical and Mental Health Summary Scales: A User's Manual. Boston, MA: Health Assessment Lab, 1994. https://www.researchgate.net/profile/John-Ware-6/publication/292390260_SF-

36_Physical_and_Mental_Health_Summary_Scales_a_User\%27s_Manual/links/5af580264585157136caee31/SF-36-Physical-and-Mental-HealthSummary-Scales-a-Users-Manual.pdf.

21. Bullinger M, Alonso J, Apolone G, et al. Translating health status questionnaires and evaluating their quality: the IQOLA Project approach. International Quality of Life Assessment. J Clin Epidemiol. 1998;51:913-23.

22. Yao G, Wang JD, Lin MR, et al. The WHOQOL-Bref, Taiwan: Manual and Development, 1 st ed. Taipei, Taiwan: the WHOQOL-Bref, Taiwan Task Force in Psychology department, National Taiwan University, 2000. [in Chinese].

23. The World Health Organization Quality of Life assessment (WHOQOL). position paper from the World Health Organization. Soc Sci Med. 1995 Nov;41:1403-9. doi:10.1016/0277-9536(95)00112-k.

24. WHO Quality of Life Assessment Group. What quality of life? / The WHOQOL Group. World Health Forum 1996;17:354-356. https://apps.who.int/iris/handle/10665/54358

25. The World Health Organization Quality of Life Assessment (WHOQOL). development and general psychometric properties. Soc Sci Med. 1998 Jun;46:1569-85. doi:10.1016/s0277-9536(98)00009-4.

26. Yao G, Chung CW, Yu CF, Wang JD. Development and verification of validity and reliability of the WHOQOL-BREF Taiwan version. J Formos Med Assoc. 2002 May;101(5):342-51. http://www.fma.org.tw/jfma/PDF/2002-101/Issue\%2005/A6.pdf. PMID: 12101852.

27. Hwang HF, Liang WM, Chiu YN, Lin MR. Suitability of the WHOQOL-BREF for community-dwelling older people in Taiwan. Age Ageing. 2003;32:593-600. doi:10.1093/ageing/afg102.

28. Lam CL, Gandek B, Ren XS, Chan MS. Tests of scaling assumptions and construct validity of the Chinese (HK) version of the SF-36 Health Survey. J Clin Epidemiol. 1998;51:1139-47. doi:10.1016/s0895-4356(98)00105-X.

29. Ren XS, Amick B 3rd, Zhou L, Gandek B. Translation and psychometric evaluation of a Chinese version of the SF-36 Health Survey in the United States. J Clin Epidemiol. 1998;51:1129-38. doi:10.1016/s0895-4356(98)00104-8.

30. Fuh JL, Wang SJ, Lu SR, Juang KD, Lee SJ. Psychometric evaluation of a Chinese (Taiwanese) version of the SF-36 health survey amongst middle-aged women from a rural community. Qual Life Res. 2000;9:675-83. doi:10.1023/a:1008993821633.

31. Azen SP, Palmer JM, Carlson M, et al. Psychometric properties of a Chinese translation of the SF-36 health survey questionnaire in the Well Elderly Study. J Aging Health. 1999;11:240-51. doi:10.1177/089826439901100206.

32. Tseng HM, Lu JFR, Tsai YJ. Assessment of health-related quality of life II: norming and validation of SF-36 Taiwan Version. Taiwan J Public Health. 2003;22:512-8. https://www.researchgate.net/publication/279621013_Assessment_of_healthrelated_quality_of_life_in_Taiwan_II_Norming_and_validation_of_SF-36_Taiwan_ver. [in Chinese].

33. Ware JE, Snow KK, Kosinski M. SF-36 health survey: Manual and Interpretation Guide. Lincoln, RI: Quality Metric Incorporated, $1993,2000$.

34. McDowell I, Newell C. Measuring Health: a guide to rating scales and questionnaires. second ed. New York: Oxford University Press; 1996.

35. Folstein MF, Folstein SE, McHugh PR. "Mini-mental state." A practical method for grading the cognitive state of patients for the clinician. J Psychiatr Res. 1975;12:189-98. doi:10.1016/0022-3956(75)90026-6.

36. Washburn RA, Smith KW, Jette AM, Janney CA. The physical activity scale for the elderly (PASE): development and evaluation. J Clin Epidemiol 1993;46:153-62. https://doi.org/10.1016/0895-4356(93)90053-4. https://www.sciencedirect.com/science/article/pii/0895435693900534.

37. Sun WJ, Chi LY, Jen IA, Tsai YJ, Chou TM, Chou P. Short Form-36 and World Health Organization quality of life-bref version: which one should be chosen for community-dwelling elders in south Taiwan? Prim Care Commun Psychiatry. 2008;13:168-76.

38. Mulsant BH, Ganguli M, Seaberg EC. The relationship between self-rated health and depressive symptoms in an epidemiological sample of communitydwelling older adults. J Am Geriatr Soc. 1997;45:954-8. doi:10.1111/j.1532-5415.1997.tb02966.x.

39. Lin SI, Chang KC, Lee HC, Yang YC, Tsauo JY. Problems and fall risk determinants of quality of life in older adults with increased risk of falling. Geriatr Gerontol Int. 2015;15:579-87. doi:10.1111/ggi.12320.

40. Li F, Fisher KJ, Harmer P, McAuley E, Wilson NL. Fear of falling in elderly persons: association with falls, functional ability, and quality of life. J Gerontol B Psychol Sci Soc Sci. 2003;58:P283-90. doi:10.1093/geronb/58.5.p283.

41. Schoene D, Heller C, Aung YN, Sieber CC, Kemmler W, Freiberger E. A systematic review on the influence of fear of falling on quality of life in older people: is there a role for falls? Clin Interv Aging. 2019;14:701-19. doi:10.2147/CIA.S197857.

42. Scaf-Klomp W, Sanderman R, Ormel J, Kempen GI. Depression in older people after fall-related injuries: a prospective study. Age Ageing. 2003 Jan;32:8894. doi: 10.1093/ageing/32.1.88. 
43. Hsu HC, Wu SC, Chiang TL. The impact of fall on health-related quality of life among the elderly in community. Chin J Public Health (Taipei). 1996;15:525-32.

44. Yeh EK, Hwu HG, Lin TY. Mental Disorders in Taiwan: epidemiological studies of community population. In: Lin TY, Tseng WS, Yeh EK, editors. Chinese Society and Mental Health. New York: Oxford University Press. Chapter 18; 1995. pp. 247-65.

45. Sun WJ, Chi LY, Jen IA, et al. Health-related quality of life survey of a general population living in a community-dwelling elders in South Taiwan. Prim Care Commun Psychiatry. 2007;12:137-44.

46. Szabó Á, Klokgieters SS, Kok AAL, van Tilburg TG, Huisman M. Psychological resilience in the context of disability: a study with Turkish and Moroccan young-old immigrants living in the Netherlands. Gerontologist. 2020 Feb 24;60:259-269. doi: 10.1093/geront/gnz129.

47. Stineman MG, Xie D, Pan Q, et al. All-cause 1-, 5-, and 10-year mortality in elderly people according to activities of daily living stage. J Am Geriatr Soc. 2012;60:485-92. doi:10.1111/j.1532-5415.2011.03867.x.

48. Albrecht GL, Devlieger PJ. The disability paradox: high quality of life against all odds. Soc Sci Med. 1999;48:977-88. doi:10.1016/s0277-9536(98)004110 .

49. Wojtek J, Chodzko-Zajko DN, Proctor MA, Fiatarone Singh CT, Minson CR, Nigg GJ, Salem, James S. Skinner. Exercise and Physical Activity for Older Adults. Med Sci Sports Exerc. 2009;41:1510-30. doi:10.1249/MSS.0b013e3181a0c95c.

50. Vaapio VSariS, Salminen MJ, Ojanlatva A, Kivelä S-L. Quality of life as an outcome of fall prevention interventions among the aged: a systematic review. Eur J Public Health. 2009;19:7-15. https://doi.org/10.1093/eurpub/ckn099.

\section{Supplementary Files}

This is a list of supplementary files associated with this preprint. Click to download.

- TableS1Definitionsofcovariates.docx

- Tables2Comparisonofmeansubscalescoresbycovariate.docx 